\title{
Epidemiology and antimicrobial susceptibility of invasive bacterial infections in children - a population-based study from Norway
}

Christian Magnus Thaulow (MD) ${ }^{1,2}$, Paul Christoffer Lindemann (MD) $)^{1,3}$, Claus Klingenberg $(\mathrm{PhD})^{4,5}$, Dag Berild $(\mathrm{PhD})^{6}$, Hege Salvesen Blix $(\mathrm{PhD})^{7,8}$, Tor Åge Myklebust $(\mathrm{PhD})^{9}$, Stig Harthug $(\mathrm{PhD})^{1,10}$

\footnotetext{
1 Department of Clinical Science, University of Bergen, P.O.Box 7804, 5020, Bergen, Norway

2 Department of Pediatrics and Adolescence Medicine, Haukeland Universiy Hospital, P.O.Box 1400, 5021, Bergen, Norway

${ }^{3}$ Department of Microbiology, Haukeland University Hospital, P.O.Box 1400, 5021, Bergen, Norway

${ }^{4}$ Department of Health Sciences, UiT-The Arctic University of Norway, 9037, Tromsø, Norway

5 Department of Pediatrics and Adolescence Medicine, University Hospital of North Norway, Troms $\varnothing$, Norway

${ }^{6}$ Department of Clinical Medicine, University of Oslo, P.O.Box 1077, 0316, Oslo, Norway

${ }^{7}$ Department of Pharmacy, University of Oslo, P.O.Box 1068 Blindern, 0316, Oslo, Norway

${ }^{8}$ Department of Drug Statistics, Norwegian Institute of Public Health, P.O.Box 222, 0213, Oslo, Norway

${ }^{9}$ Department of Research and Innovation, Møre and Romsdal Hospital Trust, P.O.Box 1600, 6026, Ålesund, Norway

${ }^{10}$ Department of Research and Development, Haukeland University Hospital, P.O.Box 1400, 5021, Bergen, Norway
}

\section{Corresponding author}

Christian Magnus Thaulow, Department of Pediatrics and Adolescence Medicine, Haukeland University Hospital, Jonas Lies vei 65, P.O.Box 1400, 5021 Bergen, Norway Telephone: +47 99223399, Fax: +47 55975147, E-mail address: cmt85@hotmail.com

\section{Conflicts of interest and source of funding}


The authors have no conflicts of interests to declare. Christian Magnus Thaulow has received a PhD-grant (\# 154835) from the University of Bergen.

\section{Contributorship}

CMT, DB and HSB were involved in the development of the protocol. CMT and DB was responsible for the data collection. CMT, TAM, SH and PCL quality assured the data and did the analyses. CMT and CK wrote the first drafts. All the authors contributed to the interpretation of the data and revisions of the manuscript and approved the final version of the manuscript.

Key words: antimicrobial resistance; pediatric antibiotic stewardship; invasive infections; pediatric sepsis; bacterial isolates

Abbreviated title: Epidemiology and antimicrobial susceptibility of invasive infections in children

Running head title: Invasive bacterial isolates in Norwegian children

Abbreviations used in the paper: Antimicrobial susceptibility testing (AST), Cerebrospinal fluid (CSF), Minimum inhibitory concentration (MIC), Coagualse-negative staphylococci (CoNS), Norwegian Surveillance System of Antimicrobial Resistance (NORM), Susceptible (S), Intermediate restistant (I), Resistant (R), Streptococcus agalactiae (GBS), confidence interval (CI), interquartile range (IQR), Systemic Inflamatory Response Syndrome (SIRS). 
Word count main text (introduction-conclusion): 3212

Word count in the abstract: 217

Number of Tables: 2

Number of Figures: 4

Number of Supplemental Digital Content: 4 


\section{Abstract}

Objective: To describe epidemiology and antimicrobial susceptibility testing (AST) data of bacteria causing invasive infections in Norwegian children (0-18 years).

Methods: Population-based observational study using prospectively collected AST data from the Norwegian Surveillance System of Antimicrobial Resistance from 2013 to 2017. We included all clinically relevant bacterial isolates (blood and cerebrospinal fluid), and compared incidence of invasive infections and AST data in isolates from children and adults. Results: We included 1173 isolates from children and 44561 isolates from adults. Staphylococcus aureus accounted for 220/477 (46.2\%, 95\% CI 41.6-50.7) of all isolates in schoolchildren (6-18 years). Compared to Streptococcus pneumonia isolates from adults ( $N=2674)$, we observed higher non-susceptibility rates to penicillin in isolates from children $(\mathrm{N}=151), 11.9 \%$ versus $5.8 \%, \mathrm{p}<0.01$; and also higher resistance rates to erythromycin $(11.3 \%$ versus $4.9 \%, \mathrm{p}<0.01)$, clindamycin $(9.3 \%$ versus $3.6 \%, \mathrm{p}<0.001)$ and trimethoprim/sulfamethoxazole (17.9\% versus 6.4\%, p<0.001). Compared to Escherichia coli isolates in adults $(\mathrm{N}=9073)$, we found lower rates of ESBL in isolates from children $(\mathrm{N}=212)$, $2.4 \%$ versus $6.4 \%, \mathrm{p}<0.05$.

Conclusion: The study indicates the importance of microbiological surveillance strategies in children and highlights the need for pediatric AST data. The high rates of non-susceptibility to commonly used antibiotics among $S$. pneumoniae in children and the high burden of invasive S. aureus infections in schoolchildren calls for modifications of Norwegian guidelines. 


\section{Introduction}

Bacterial infections are one of the most frequently causes of death in children, ${ }^{1,2}$ and increasing antimicrobial resistance is a major health concern worldwide. ${ }^{3}$ Surveillance of epidemiology and antimicrobial susceptibility testing (AST) data for bacteria causing serious infections is of high importance, ${ }^{4}$ but data specific for children are often lacking, also in Norway. ${ }^{5}$ Specific antibiograms for children improve treatment quality, ${ }^{6}$ and pediatric surveillance programs are recommended. ${ }^{7,8}$

The distribution of the most frequent bacteria recovered in pediatric bloodstream infections varies in different countries and settings ${ }^{8-11}$ and with age. ${ }^{1,9}$ Studies comparing AST data in bacterial isolates from children versus adults are limited. ${ }^{8,12,13}$ A Canadian study reported lower rates of resistance to commonly used antibiotics in Escherichia coli and Staphylococcus aureus isolates from children than adults. ${ }^{12}$ A European study reported higher resistance rates to macrolides in pediatric Streptococcus pneumonia blood isolates than in adult isolates. ${ }^{8}$

Norway is a high-income country with low rates of antimicrobial resistance. ${ }^{5,14}$ Empirical recommendations for antibiotic regimen in children emphasize penicillin for pneumonia and gentamicin combined with penicillin or ampicillin for sepsis. ${ }^{15}$ However, adherence rate to the guideline varies. $^{16,17}$

The aims of this study were to report the incidence of invasive bacterial infections, the distribution of causative pathogens and AST-data, in Norwegian children compared to adults. 


\section{Materials and Methods}

\section{Data collection and bacterial isolates}

This is an observational population-based study using prospectively collected data from the Norwegian Surveillance System for Antimicrobial Resistance (NORM) between 2013 and 2017. NORM was established in 2003 and collects clinically relevant AST-data from different sites within defined time ranges for each bacterium. All 22 primary diagnostic laboratories and 11 reference laboratories in Norway participate in the collection. A specially designed web-based computer program (eNORM) is used for registration. The reporting of AST-data is mandatory and is regulated by the National Regulation of Resistance Registry. ${ }^{18}$ All samples from both primary care and hospitals (including 22 pediatric centers) in entire Norway are covered by these laboratories. Thus, the expected national coverage is close to $100 \%$ within the defined time ranges of collection for each bacterium. Patients with more than one phenotypically identical isolate of the same species from the same site within one month are registered with only one isolate, but if the same isolate is observed in both blood and spinal fluid, they are registered as two isolates. Results from AST are interpreted in accordance with clinical breakpoints from EUCAST. ${ }^{19}$ Further details on testing are described in the NORM reports. ${ }^{5}$

We included all relevant systemic isolates from blood and cerebrospinal fluid (CSF), Table 1. NORM also collects isolates from urine, wounds and the respiratory tract, but these are not registered in relation to systemic infections and were therefor not included in our study. Data on Coagulase-negative staphylococci (CoNS) and Viridans group streptococci were not reported to NORM in the collection period and could not be included in our analyses, but these are also 
often defined as contaminants in pediatric blood culture studies. ${ }^{20}$ We excluded anaerobic isolates, as there were not a single isolate obtained in children, during a 12 months collection period. This can be explained by less frequently use of anaerobic blood culture bottles among children, but also by less observations of anaerobe bacteria in children. ${ }^{21}$

Data on children (0-18 years), extracted from NORM, included birth month and year, county of residence, laboratory name, date of culture, name of antibiotic and the minimum inhibitory concentration (MIC) value. We divided the children in three different age categories; infants (0-1 years of age, up to the month of turning one year); preschool children (1-6 years of age, from the first month after turning one year to the month of turning six years); schoolchildren (6-18 years of age, from the first month after turning six years to the month of turning 18 years). Additionally, we also report selected data separately for infants 0-3 months of age (up to the month of turning three months). The isolates from adults were separated from the year-specific NORM reports by subtracting the pediatric isolates from the total number of isolates presented in the reports. ${ }^{5}$ This was done separately for each bacteria-antibiotic combination so that all pediatric results were eliminated. In 41 pediatric Streptococcus agalactiae (GBS) isolates and in one $S$. aureus isolate, susceptibility data were missing. These isolates were included in the demographic overview for children, but for comparison of resistance rates, they remained in the adult group because it was not possible to extract them.

\section{Definitions, analyses and statistics}

All data and specifically the translation into susceptibility pattern were quality assured. We used the EUCAST clinical breakpoints corresponding to the year after data collection to define susceptibility into three categories: susceptible (S), intermediate resistant (I) or resistant (R). We 
used the old SIR definition since we used historical data and breakpoints. Non-susceptibility (NS) rate was defined as isolates being I or R, and was only used in relation to $S$. pneumoniae/penicillin, as this is a well-established method of describing susceptibility pattern for this combination. ${ }^{22}$ We used the non-meningitis breakpoints for penicillin. ${ }^{19}$

Demographic data were described in numbers; age groups were described with corresponding percentages and the different bacteria in children were described with corresponding risk ratio (RR) and $95 \%$ confidence intervals (CI) compared to adults. As an example, RR for E. coli was calculated as the rate of all E. coli isolates deriving from children divided by the rate of all isolates deriving from adults. The $95 \% \mathrm{CI}$ were calculated by generating the natural $\log (\mathrm{Ln})$ of the RR and then the antilog of the upper and lower limits of the CI for Ln (RR).

As some bacteria were not sampled for five fully years, we estimated the total number by multiplying the number of isolates obtained for each bacterium with the factor needed to hypothetically get five complete years of registration data. These were used to describe distribution of bacteria and crude incidence of culture-confirmed bacterial infections based on census data from Statistics Norway. ${ }^{23}$ We also estimated the age-standardized incidence, using the European standard population as reference. ${ }^{24}$ We excluded Proteus spp., Enterobacter spp., and Pseudomonas aeruginosa from the incidence calculation because we regarded the collection period too short for these more rarely detected species. Both the distribution of isolates and the incidence rates were presented as figures and reported as percentages with corresponding 95\% CI (distribution) and as number per 100000 inhabitants in Norway (incidence). 
All pediatric isolates were analyzed according to susceptibility for relevant antibiotics. For comparisons with adults, we included bacteria with more than 50 isolates, and we compared the proportion of isolates being R. The exception was S. pneumoniae where we compared the NS rate to penicillin. Resistance pattern were described in number and percentages with corresponding 95\% CI. We also performed year-by-year sensitivity analyses comparing resistance rates in all bacteria-antibiotic combinations with at least five $\mathrm{R}$ isolates in total. For $E$. coli, S. aureus and S. pneumoniae, we also compared resistance rates within our three defined pediatric age categories and for S. pneumoniae also the median MIC values for penicillin with corresponding interquartile range (IQR) between infants and older children.

For comparison of proportions, we based the statistical tests on two-way frequency tables including the observed frequencies and the expected frequencies. The expected frequency in a two-way frequency table is: (row total $\mathrm{x}$ column total) / total number of observations. If any expected frequencies were $<5$ we used Fisher`s exact test and in all other cases we used a chisquare test. Comparison of MIC values were performed using a Mann-Whitney U test. We used Stata SE version 16.1 for analyses. A p-value $<0.05$ was considered significant.

\section{Ethics}

The data were collected according to the National Regulation of Resistance Registry, ${ }^{18}$ and was approved by the data protection official at Haukeland University Hospital (ID 1075).

\section{Results}

\section{Epidemiology}


In total 1173 isolates (1144 from blood, 29 from CSF) were included from children, compared to 27735 isolates (27 621 from blood, 114 from CSF) from adults. Four percent of all blood culture isolates and $20.3 \%$ of all CSF isolates came from children (Table 2). Infants (0-12 months) accounted for $566(48.2 \%)$ of the pediatric isolates, whereof $449(79.3 \%)$ came from the age group 0-3 months. Of 181 GBS isolates, 175 (96.7\%) came from infants 0-3 months of age. Estimated annual crude national incidence rate of invasive bacterial infections in children (excluding Proteus spp, Enterobacter spp. and Pseudomonas Aeruginosa) was 26.4 per 100000 (95\% CI 23.6-29.5), corresponding to an age-standardized incidence rate of 26.2 per 100000 (95\% CI 23.4-29.4). Incidence was strongly related to age, infants presenting with the highest rate, 274.4 per 100000 (95\% CI 234.2-320.2) (Figure 1). Age-standardized incidence for $S$. aureus was 7.0 per 100000 (95\% CI 5.6-8.7). Figure 2 show that E. coli and GBS dominated among infants (58.1\%, 95\% CI 54.7-61.5), S. aureus and S. pneumoniae dominated among preschool children (40.7\%, 95\% CI 35.3-46.2), and S. aureus dominated among schoolchildren (46.2\%, 95\% CI 41.6-50.7). The Enterococcus faecalis/faecium ratio was 64/9 (7.1) in children and 2013/865 (2.3) in adults.

\section{Resistance rates}

Figure 3 highlights differences between children and adults. For a detailed description of resistance pattern in children compared to adults, see Supplementary Digital Content 1. For yearby-year resistance rates and susceptibility pattern in pediatric isolates not included for comparison, see Supplementary Digital Content 2. 
Compared to S. pneumoniae isolates from adults ( $\mathrm{N}=2674)$, we observed higher NS rates in isolates from children $(\mathrm{N}=151)$ to penicillin, $11.9 \%$ versus $5.8 \%, \mathrm{p}<0.01$. Two of the $S$. pneumoniae isolates from children were R, and 16 were I. All S. pneumoniae isolates from children that were collected from the CSF were $\mathrm{S}(\mathrm{MIC} \leq 0.06)$ to penicillin. Compared to $S$. pneumoniae isolates from adults, we also revealed higher resistance rates in isolates from children to erythromycin $(11.3 \%$ versus $4.9 \%, \mathrm{p}<0.01)$, clindamycin $(9.3 \%$ versus $3.6 \%, \mathrm{p}$ $<0.001)$ and trimethoprim/sulfamethoxazole $(17.9 \%$ versus $6.4 \%, \mathrm{p}<0.001)$. Out of the 18 isolates expressing NS to penicillin, six were resistant to all the antibiotics mentioned above, five were resistant to only erythromycin and clindamycin and three isolates were resistant to only trimethoprim/sulfamethoxazole. None of the pediatric S. pneumoniae isolates were R to cefotaxime, but four $(2.6 \%)$ were I.

Compared to GBS isolates from adults $(\mathrm{N}=895)$, we observed higher resistance rates in isolates from children $(\mathrm{N}=143)$ to erythromycin $(29.4 \%$ versus $17.1 \%, \mathrm{p}<0.001)$ and clindamycin $(25.2 \%$ versus $11.6 \%$, p $<0.001)$. In S. aureus isolates from children, we observed only one MRSA positive case $(0.3 \%)$ out of 330 isolates. Compared to $E$. coli isolates from adults $(\mathrm{N}=9073)$, we observed lower rates of ESBL production in isolates from children $(\mathrm{N}=212), 2.4 \%$ versus $6.1 \%$, $\mathrm{p}<0.05$. All five ESBL isolates in children were $\mathrm{S}$ to piperacillin-tazobactam and meropenem. Compared to $E$. coli isolates from adults, we also observed lower resistance rates to ciprofloxacin in isolates from children, $7.5 \%$ versus $13.0 \%, \mathrm{p}<0.05)$.

Resistance rates within the children group are shown in Supplemental Digital Content 3. For $S$. pneumoniae, NS rate to penicillin was $5.0 \%$ (95\% CI 0.6-16.9) in isolates from infants, $13.7 \%$ 
(95\% CI 6.8-23.8) from preschool children and 15.8\% (95\% CI 6.0-31.3) from schoolchildren.

The median penicillin MIC value for S. pneumoniae were lower in infants (0.016, IQR 0.016) than in older children $(0.032$, IQR 0.016$), \mathrm{p}<0.01$. For E. coli, resistance rate to gentamicin was $11.3 \%$ (95\% CI 4.3-23.0) in schoolchildren.

\section{Discussion}

To our knowledge, this is the first study from the Nordic countries describing national epidemiology and susceptibility pattern in pediatric invasive bacterial isolates.

The estimated annual incidence of invasive bacterial infections in Norway (age 0-18, 26.2/100 000) was very similar to data on blood culture proven sepsis in Switzerland (age 0-16, 25.1/100 000). ${ }^{1}$ However, the annual incidence for infants was somewhat higher in our study $(274.4 / 100$ 000) compared to the Swiss study (231.3/100 000). This could mirror that the latter only included isolates associated with clinical proven sepsis (by SIRS criteria). On the other hand, a substantial proportion of isolates (such as CoNS) were not included in our estimation. CoNS are often regarded as contamination, but may cause infections in immunosuppressed children. ${ }^{25}$

Age stratified distribution of pathogens from children were in the same range as in a large Swiss study. ${ }^{1}$ The E. faecalis/faecium ratio was high (7.1) in our study compared to a European pointprevalence survey (1.9). ${ }^{8}$ Given that E. faecium mostly causes nosocomial infections, ${ }^{26}$ this finding is supported by the soemwhat lower rate of nosocomial infections among children in 
Norwegian hospitals (19.8\%) compared to the average rates reported in a selection of European countries $(27.6 \%) .{ }^{16} 27$

In our study, the incidence of invasive bacterial infections was lower in children (except infants) than in adults. Antibiotic administration prior to first blood culture could stop bacteria from growing. A study in Norwegian children revealed that any microbiological testing was missing in $23 \%$ of children before start of antibiotic treatment for any indications. ${ }^{16}$ In children, blood culture procedures are more challenging than in most adults, which may lead to antibiotic administration without a corresponding blood culture. Especially during transport to hospital (when circumstances is challenging), this is relevant. A recently published study reported that multiple blood cultures with age adjusted volume prior to antibiotics increased the chance of pathogen isolation in children. ${ }^{28}$ Regarding pattern of antibiotic use, reports from Norwegian hospitals show that children use less broad-spectrum antibiotics compared to the entire population. ${ }^{5,16}$. This is relevant since detection of pathogen is more difficult if broad-spectrum antibiotics are administrated before blood culture is obtained.

Empirical antibiotic guidelines for pediatric sepsis in Norway (gentamicin plus penicillin/ampicillin) are based on low resistance rates, a long treatment tradition favoring this regime and by a limited number of studies. ${ }^{25,29,30}$ In neonates, this regime is applied world-wide, but for older children most guidelines emphasizes broad-spectrum antibiotics such as thirdgeneration cephalosporins or piperazillin-tacobactam ${ }^{31,32}$. Based on the results in our study and as part of this discussion, we have compared four different empirical antibiotic regimens for pediatric sepsis in our population (Figure 4). On one side, one should aim for antibiotics 
categorized as access in the acknowledged WHO AWaRe classification system to slow down resistance, ${ }^{3}$ but one should neither underestimate the morbidity and mortality rate of sepsis for the individual patient. ${ }^{2}$ Clinical studies in children comparing the established antibiotic regime with a third-generation cephalosporin or piperacillin-tazobactam are warranted.

The high burden of $S$. aureus bacteremia among schoolchildren in our study is in line with observations from otherwise healthy Swiss children (10-16 years). ${ }^{1}$ In comparison to the annual incidence of S. aureus bacteremia reported in our study (7.0/100 000), other high-income countries have reported incidences from 3.7 to $14.4 / 100000 .{ }^{1,33}$ Fatality of invasive S. aureus infections in children is considerable, $4.7 \%$ in Australia/New Zealand. ${ }^{33}$ Thus, adequately covering of $S$. aureus should be high priority in empirical guidelines. Many invasive $S$. aureus infections present with typical infection-sites such as bone and soft-tissue, but a notable proportion $\left(36 \%{ }^{33}\right)$ presents with no or less typical organ specific symptoms. Gentamicin resistance was low in S. aureus isolates in our population, but there is a lack of evidence using this drug as monotherapy for other than Enterobacterales. ${ }^{34}$ Thus, the empirical sepsis regime in Norway could be problematic. To continue using antibiotics listed as access in the WHO AWaRe classification system, ${ }^{35}$ we speculate whether gentamicin combined with a narrowspectrum beta-lactamase stable penicillin (such as cloxacillin) could be suitable for initial treatment of suspected sepsis in schoolchildren. Another option is to use a first-generation cephalosporin.

We could not find other studies reporting higher NS rate to penicillin in invasive S. pneumoniae isolates from children than adults, but a Canadian study from 2012 (including both blood and 
respiratory tract isolates) observed that a higher proportion of isolates from children than adults had MIC values $>1.0 \mathrm{mg} / \mathrm{L} .{ }^{12}$ Opposite to our results, one study observed higher NS rates in infants $(20.6 \%)$ compared to older children $(10.6 \%) .{ }^{8}$ Our observation of more resistance in isolates from children to both erythromycin, clindamycin and trimethoprim/sulfamethoxazole is not mirrored in other comparative studies. ${ }^{8,12}$ Particularly striking was the high resistance rate (17.9\%) to trimethoprim/sulfamethoxazole, reflected by high use of this agent in Norwegian children. ${ }^{36}$ The 13 valent pneumococcal conjugate vaccine was introduced in the Norwegian children vaccine program in 2011. A population-based study reported an increase in nonsusceptible clones in invasive pneumococcal disease that was mainly non-vaccine serotypes imported to Norway from 2011-2016. ${ }^{22}$ Susceptibility pattern in these serotypes corresponded to our observation.

Despite the high NS rate in S. pneumoniae isolates, we argue that penicillin should continue as first-line empirical drug in severe pneumonia because most isolates were intermediate resistant, and relevant alternatives have even higher odds of treatment failure or an unfavorable ecological profile. However, one should aim for high dose exposure (up to $50 \mathrm{mg} / \mathrm{kg}$ every four hours). ${ }^{37}$ For the future, serotype independent vaccines may help combat invasive pneumococcal infections. $^{38}$

Our observation of lower ESBL rates in E. coli isolates from children than from adults is comparable with studies from North America, ${ }^{12,39}$ and the lower resistance rate to ciprofloxacin is even more dominant in other reports. ${ }^{8,12}$ In Canada, gentamicin resistance in isolates from children was reported lower than in adults, ${ }^{12}$ while a European study reported the opposite. ${ }^{8}$ The 
high resistance rates in $E$. coli isolates from schoolchildren to multiple antibiotic classes observed in our study is of concern, but it corresponds to other observations of increasing E. coli resistance during childhood. ${ }^{8}{ }^{40}$ Despite the latter, our study supports that gentamicin continues as an appropriate drug for Enterobacterales for most children in our population.

In this large study, we used national prospectively collected data from a high-quality register using identical methods in all data collection. In contrast to another study that used the entire population as reference group, ${ }^{8}$ we have compared resistance rates in two homogenous groups of children and adults. The lack of clinical data is a limitation when interpreting the results of the study. We acknowledge that studies with focus on the connection between microbiological findings and clinical parameters are needed. Unfortunately, we could not include all microbes with fully registration periods. We compensated by calculating an estimated number of total isolates, but we excluded bacteria that were not collected $\geq 50 \%$ of the entire period (2013-2017) from the incidence calculation. The $41 \mathrm{GBS}$ isolates from children that had to remain in the adult group has to be considered when interpreting the resistance rates. Finally, we had to use breakpoints corresponding to the year of the different NORM reports because we did not have MIC values available for the adult population. However, we also analyzed all isolates from children in accordance with the 2020 breakpoints from EUCAST and we revealed different resistance rate in only four bacteria/antibiotic combinations and in total only eight single isolates was added or subtracted in the R category, see Supplemental Digital Content 4.

\section{Conclusion}


This study gives valuable microbiological data in characteristics of pediatric invasive bacterial isolates in a high-income country, emphasizing the need for separate surveillance strategies in children, and should motivate for more publications of pediatric AST data. We observed important aspects to be considered when revising pediatric antibiotic guidelines in Norway; the high burden of invasive S. aureus isolates in schoolchildren and the higher degree of NS (penicillin) and resistance (erythromycin, clindamycin and trimethoprim/sulfamethoxazole) in invasive $S$. pneumoniae isolates from children than from adults. 


\section{References}

1. Agyeman PKA, Schlapbach LJ, Giannoni E et al. Epidemiology of blood culture-proven bacterial sepsis in children in Switzerland: a population-based cohort study. Lancet Child Adolesc Health 2017; 1: 124-33.

2. Boeddha NP, Schlapbach LJ, Driessen GJ et al. Mortality and morbidity in communityacquired sepsis in European pediatric intensive care units: a prospective cohort study from the European Childhood Life-threatening Infectious Disease Study (EUCLIDS). Crit Care 2018; 22: 143.

3. World Health Organization (WHO). Global action plan on antimicrobial resistance. 2015. https://apps.who.int/iris/handle/10665/193736. (accessed May 02 2020).

4. Cornaglia G, Hryniewicz W, Jarlier V et al. European recommendations for antimicrobial resistance surveillance. Clin Microbiol Infect 2004; 10: 349-83.

5. NORM/NORM-VET 2013-2017. Usage of Antimicrobial Agents and Occurrence of Antimicrobial Resistance in Norway. Yearly reports. https://unn.no/fag-og-forskning/normnorsk-overvakingssystem-for-antibiotikaresistens-hos-mikrober\#rapporter. (accessed Sep 10 2020).

6. Boggan JC, Navar-Boggan AM, Jhaveri R. Pediatric-specific antimicrobial susceptibility data and empiric antibiotic selection. Pediatrics 2012; 130: e615-22. 
7. Tamma PD, Robinson GL, Gerber JS et al. Pediatric antimicrobial susceptibility trends across the United States. Infect Control Hosp Epidemiol 2013; 34: 1244-51.

8. Bielicki JA, Lundin R, Sharland M et al. Antibiotic Resistance Prevalence in Routine Bloodstream Isolates from Children's Hospitals Varies Substantially from Adult Surveillance Data in Europe. Pediatr Infect Dis J 2015; 34: 734-41.

9. Wilson J, Elgohari S, Livermore DM et al. Trends among pathogens reported as causing bacteraemia in England, 2004-2008. Clin Microbiol Infect 2011; 17: 451-8.

10. Larru B, Gong W, Vendetti N et al. Bloodstream Infections in Hospitalized Children: Epidemiology and Antimicrobial Susceptibilities. Pediatr Infect Dis J 2016; 35: 507-10.

11. Spaulding AB, Watson D, Dreyfus J et al. Epidemiology of Bloodstream Infections in Hospitalized Children in the United States, 2009-2016. Clin Infect Dis 2019; 69: 995-1002.

12. Adam HJ, Baxter MR, Davidson RJ et al. Comparison of pathogens and their antimicrobial resistance patterns in paediatric, adult and elderly patients in Canadian hospitals. J Antimicrob Chemother 2013; 68 Suppl 1: i31-7. 
13. Oteo J, Baquero F, Vindel A et al. Antibiotic resistance in 3113 blood isolates of Staphylococcus aureus in 40 Spanish hospitals participating in the European Antimicrobial Resistance Surveillance System (2000-2002). J Antimicrob Chemother 2004; 53: 1033-8.

14. European Centre for Disease Prevention and Control. Surveillance of antimicrobial resistance in Europe 2018. Stockholm: ECDC; 2019. https://www.ecdc.europa.eu/sites/default/files/documents/surveillance-antimicrobial-resistanceEurope-2018.pdf. (Accessed Sep 16 2020).

15. Norwegian Pediatric Association. Akuttveileder i Pediatri (in Norwegian). 2013. https://www.helsebiblioteket.no/pediatriveiledere (accessed Oct 23 2020).

16. Thaulow CM, Berild D, Eriksen BH et al. Potential for More Rational Use of Antibiotics in Hospitalized Children in a Country With Low Resistance: Data From eight Point Prevalence Surveys. Pediatr Infect Dis J 2019; 38: 384-9.

17. Thaulow CM, Blix HS, Eriksen BH et al. Using a period incidence survey to compare antibiotic use in children between a university hospital and a district hospital in a country with low antimicrobial resistance: a prospective observational study. BMJ Open 2019; 9: e027836.

18. Ministry of Health and Care Services. Forskrift om innsamling og behandling av helseopplysninger i Norsk overvåkningssystem for resistens hos bakterier, sopp og virus 
(Resistensregisterforskriften) (In Norwegian). 2004.

https://lovdata.no/dokument/SF/forskrift/2003-11-14-1353. (Accessed July 30, 2020)

19. European Commitee on Antimicrobial Susceptibility testing (EUCAS). Clinical breakpoints breakpoints and guidance. https://eucast.org/clinical_breakpoints/. (Accessed Oct 20 2020).

20. Chappell-Campbell L, Schwenk HT, Capdarest-Arest N et al. Reporting and Categorization of Blood Culture Contaminants in Infants and Young Children: A Scoping Review. J Pediatric Infect Dis Soc 2020; 9: 110-7.

21. Dien Bard J, McElvania TeKippe E. Diagnosis of Bloodstream Infections in Children. J Clin Microbiol 2016; 54: 1418-24.

22. Siira L, Vestrheim DF, Winje BA et al. Antimicrobial susceptibility and clonality of Streptococcus pneumoniae isolates recovered from invasive disease cases during a period with changes in pneumococcal childhood vaccination, Norway, 2004-2016. Vaccine 2020; 38: 545463.

23. Norway Statistics. https://www.ssb.no/en. (accessed Jun 03 2020).

24. Eurostat. Revision of the European Standard Population. 2013. Luxembourg. ISBN 978-9279-31094-2. doi:10.2785/11470. 
25. Stabell N, Nordal E, Stensvold E et al. Febrile neutropenia in children with cancer: a retrospective Norwegian multicentre study of clinical and microbiological outcome. Scand J Infect Dis 2008; 40: 301-7.

26. Arias CA, Murray BE. The rise of the Enterococcus: beyond vancomycin resistance. Nat Rev Microbiol 2012; 10: 266-78.

27. Versporten A, Bielicki J, Drapier N et al. The Worldwide Antibiotic Resistance and Prescribing in European Children (ARPEC) point prevalence survey: developing hospital-quality indicators of antibiotic prescribing for children. J Antimicrob Chemother 2016; 71: 1106-17.

28. Tran P, Dowell E, Hamilton S et al. Two Blood Cultures With Age-Appropriate Volume Enhance Suspected Sepsis Decision-Making. Open Forum Infect Dis 2020; 7: ofaa028.

29. Torfoss D, Fladhagen T, Holte $\mathrm{H}$ et al. Benzylpenicillin plus an aminoglycoside versus meropenem in neutropenic lymphoma and leukaemia patients with a suspected bacterial infection: a randomized, controlled trial. Clin Microbiol Infect 2017; 23: 179-87.

30. Torfoss D, Hoiby EA, Holte $\mathrm{H}$ et al. The Norwegian experience with penicillin G plus an aminoglycoside as initial empiric therapy in febrile neutropenia; a review. Acta Oncol 2012; 51: 433-40. 
31. National Institute for Health and Care Exellence (NICE). Sepsis; recognition, diagnosis and early management. 2016.

https://www.nice.org.uk/guidance/ng51/chapter/Recommendations\#antibiotic-treatment-inpeople-with-suspected-sepsis. (accessed Oct 20 2020).

32. Weiss SL, Peters MJ, Alhazzani W et al. Surviving sepsis campaign international guidelines for the management of septic shock and sepsis-associated organ dysfunction in children. Intensive Care Med 2020; 46: 10-67.

33. McMullan BJ, Bowen A, Blyth CC et al. Epidemiology and Mortality of Staphylococcus aureus Bacteremia in Australian and New Zealand Children. JAMA Pediatr 2016; 170: 979-86.

34. Vidal L, Gafter-Gvili A, Borok S et al. Efficacy and safety of aminoglycoside monotherapy: systematic review and meta-analysis of randomized controlled trials. J Antimicrob Chemother 2007; 60: 247-57.

35. Hsia Y, Lee BR, Versporten A et al. Use of the WHO Access, Watch, and Reserve classification to define patterns of hospital antibiotic use (AWaRe): an analysis of paediatric survey data from 56 countries. Lancet Glob Health 2019; 7: e861-e71.

36. Stordal K, Marild K, Blix HS. Bruk av antibiotika hos barn i perioden 2005-16. Tidsskr Nor Laegeforen 2017; 137. 
37. British Medical Association. BNF for children 2016-2017. 1st ed. London: BMJ Group, Pharmaceutical Press and RCPCH Publications Ltd.

38. Morais V, Texeira E, Suarez N. Next-Generation Whole-Cell Pneumococcal Vaccine. Vaccines (Basel) 2019; 7.

39. Fedler KA, Biedenbach DJ, Jones RN. Assessment of pathogen frequency and resistance patterns among pediatric patient isolates: report from the 2004 SENTRY Antimicrobial Surveillance Program on 3 continents. Diagn Microbiol Infect Dis 2006; 56: 427-36.

40. Sahuquillo-Arce JM, Selva M, Perpinan H et al. Antimicrobial resistance in more than 100,000 Escherichia coli isolates according to culture site and patient age, gender, and location. Antimicrob Agents Chemother 2011; 55: 1222-8. 


\section{Figure legends}

Figure 1) Estimated incidence rate for different age groups of invasive bacterial infections confirmed by isolates from blood/CSF in Norway. Vertical line represents the 95\% CI around the point estimate for each category. The number of isolates is estimated based on sampling from the Norwegian Surveillance System for Antimicrobial resistance (NORM) 2013-2017.

\# Bacteria included: S. aureus, S. pneumoniae, S. pyogenes, S. agalactiae, Enterococcus spp., E. coli, Klebsiella spp., H. influenza, N. meningitidis

Figure 2) Distribution of (a) bacterial species and (b) Gram-negative/Gram-positive bacteria in blood/CSF isolates in Norway for different age groups; adults $(n=44000), 0-1$ years $(n=834), 1-5$ years $(n=327), 6-18$ years $(n=477)$. The number of isolates is estimated based on sampling from the Norwegian Surveillance System for Antimicrobial resistance (NORM) 2013-2017.

Figure 3) Comparison of susceptibility pattern between invasive (blood/CSF) isolates from Norwegian children (0-18 years) and adults, (a) Gram-positive bacteria and (b) Gram-negative bacteria. 95\% CI are shown as the vertical line on the column. Penicillin NS (Pencillin nonsusceptible), SXT (Trimethoprim-sulfamethoxazol), Gentamicin Hi (High level gentamicin resistance), TZP (Piperacillin-tazobactam). Data are based on sampling from the Norwegian Surveillance System for Antimicrobial Resistance (NORM), 2013-2017. 
Figure 4) Alternative antibiotic empirical regimes for pediatric/neonatal sepsis in Norway and their expected effect on the most common bacteria. Resistance rates are based on national collected data on children (0-18 years) from blood/CSF 2013-2017. CSF; Cerebrospinal fluid

${ }^{x}$ Access and Watch antibiotics are defined by the WHO

\# If resistance rate for a certain bacteria/antibiotic combination was not available, the most appropriate category was evaluated based on resistance rates for similar antibiotics and/or available literature

${ }^{\S}$ Breakpoints for this figure are based on the 2020 version of EUCAST cut-off limits. EUCAST; European Committee on Antimicrobial Susceptibility Testing.

\section{List of Supplemental Digital Content}

Supplemental Digital Content 1: Table showing comparison of susceptibility patterns between children and adults

Supplemental Digital Content 2: Tables showing year-by-year resistance rates in children and adults, and susceptibility pattern in pediatric isolates not included for comparison

Supplemental Digital Content 3: Table showing comparison of resistance rates within the children group

Supplemental Digital Content 4: Comparison of resistance rates in blood culture isolates from Norwegian children using breakpoint from different years. 


\begin{tabular}{llllll}
\hline & $\mathbf{2 0 1 3}$ & $\mathbf{2 0 1 4}$ & $\mathbf{2 0 1 5}$ & $\mathbf{2 0 1 6}$ & $\mathbf{2 0 1 7}$ \\
& Months & Months & Months & Months & Months \\
\hline Bacteria & 9 & 9 & 9 & 9 & 9 \\
S. aureus & 12 & 12 & 12 & 12 & 12 \\
S. pneumoniae & 12 & 12 & 12 & 12 & 12 \\
S. pyogenes & - & 12 & 12 & 12 & 12 \\
S. agalactiae & 9 & 9 & 9 & 9 & 9 \\
Enterococcus spp. & 6 & 6 & 6 & 6 & 6 \\
E. coli & 9 & 9 & 9 & 9 & 9 \\
Klebsiella spp. & 12 & 12 & 12 & 12 & 12 \\
H. influenzae & 12 & 12 & 12 & 12 & 12 \\
N. meningitidis & - & - & 9 & - & - \\
P. aeruginosa & - & - & - & 9 & 9 \\
Enterobacter spp. & - & - & - & - & \\
Proteus spp. & - & & & & \\
\hline
\end{tabular}

Table 1: Collection periods for blood and cerebrospinal fluid (CSF) isolates in the Norwegian Surveillance System for Antimicrobial Drug Resistance (NORM) 2013-2017

* CSF isolates were only obtained from S. pneumonia, S. pyogenes, S. agalactiae, H. influenzae and N. meningitidis 


\begin{tabular}{lll}
\hline & Blood & CSF \\
\hline All, n & 28403 & 143 \\
Children n (\% of all) & $1144(4.0)$ & $29(20.3)$
\end{tabular}

Age groups (n, \% of paediatric isolates)

$\begin{array}{llc}<1 & 566(49.5) & 9(31.0) \\ 1-5 & 233(20.4) & 12(41.4) \\ 6-18 & 342(29.9) & 8(27.6) \\ \text { Unknown } & 3(0.3) & \end{array}$

Microbes, n (RR to adults, $95 \%$ CI)

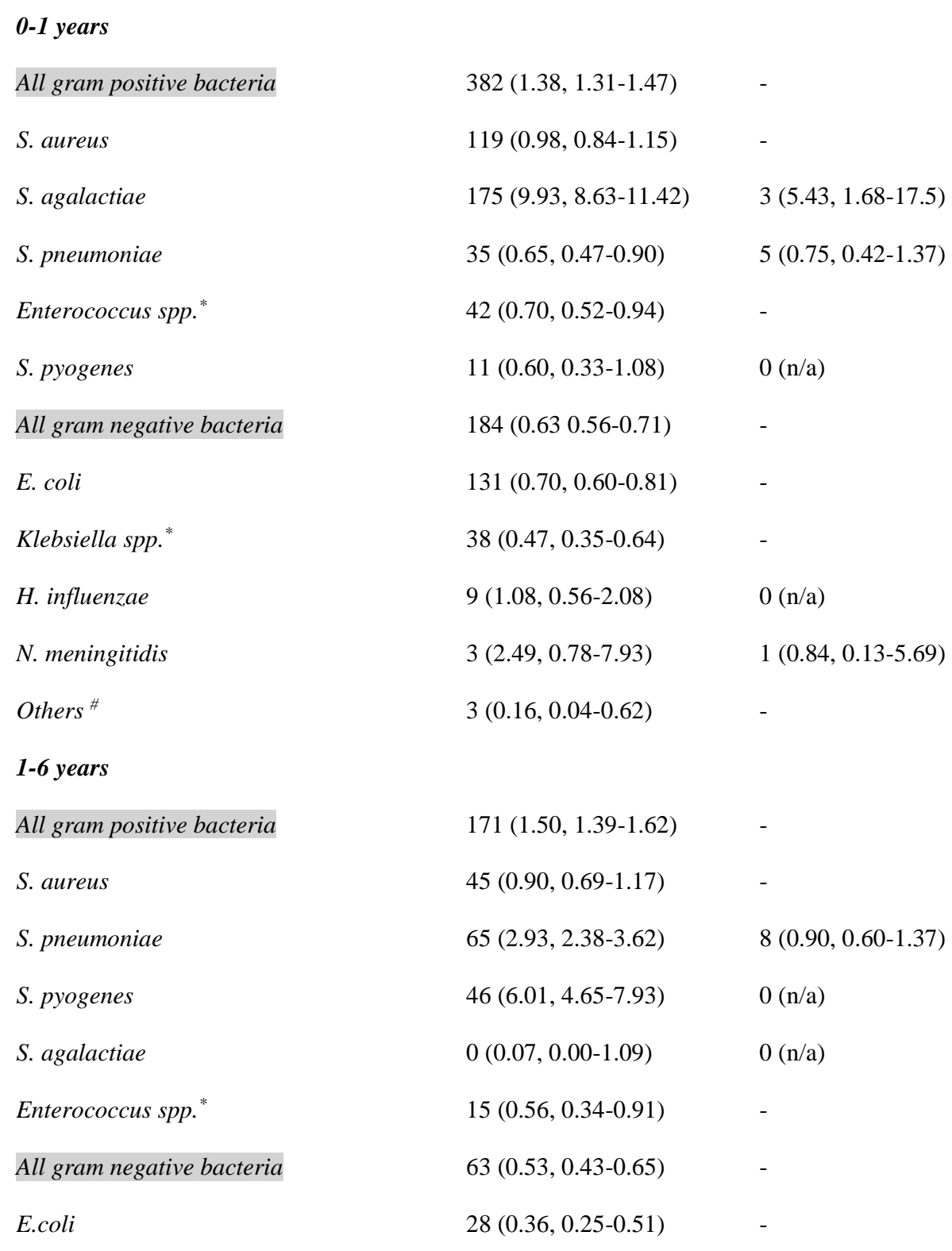




$\begin{array}{lll}\text { Klebsiella spp. } & 14(0.42,0.25-0.70) & - \\ \text { H. influenzae } & 12(3.49,1.99-6.10) & 4(4.75,1.67-13.47) \\ \text { N. } \text { meningitidis }^{*} & 4(8.03,2.94-21.95) & 1(0.84,0.13-5.69) \\ \text { Others }{ }^{\#} & 5(1.08,0.45-2.59) & - \\ \text { 6-18 years } & & \\ \text { All gram positive bacteria } & 261(1.57,1.48-1.67) & - \\ \text { S. aureus } & 165(2.26,2.02-2.53) & - \\ \text { S. pneumoniae } & 36(1.11,0.82-1.52) & 2(0.34,0.10-1.13) \\ \text { S. pyogenes } & 35(3.17,2.30-4.37) & 1(38.33,1.68-875.03) \\ \text { S. agalactiae } & 6(0.56,0.25-1.25) & 0(\mathrm{n} / \mathrm{a}) \\ \text { Enterococcus spp. } & 19(0.48,0.31-0.75) & - \\ \text { All gram negative bacteria } & 85(0.46,0.38-0.55) & - \\ \text { E. coli } & 53(0.47,0.36-0.60) & - \\ \text { Klebsiella spp. } & 18(0.37,0.24-0.58) & - \\ \text { H. influenzae } & 7(1.40,0.67-2.92) & 2(3.56,0.90-14.07) \\ \text { N. meningitidis } & 1(1.38,0.19-9.92) & 3(2.85,1.04-7.84) \\ \text { Others } & 1(0.15,0.02-1.05) & - \\ & & \\ & & \end{array}$

Table 2) Bacterial isolates from the Norwegian Surveillance System for Antimicrobial Drug Resistance (NORM) 2013-2017 - total number, main bacterial pathogens in children (0-18 years) and relative risk ratio (RR) in children to adults.

* All age gropus: E. faecalis (64)), E. faecium (9), Enterococcus spp. (3), K. pneumoniae (54), K. oxytoca (13), Klebsiella spp. (3).

\# All age groups: Proteus spp. (2), Enterobacter spp. (2), P. aeruginosa (5). 


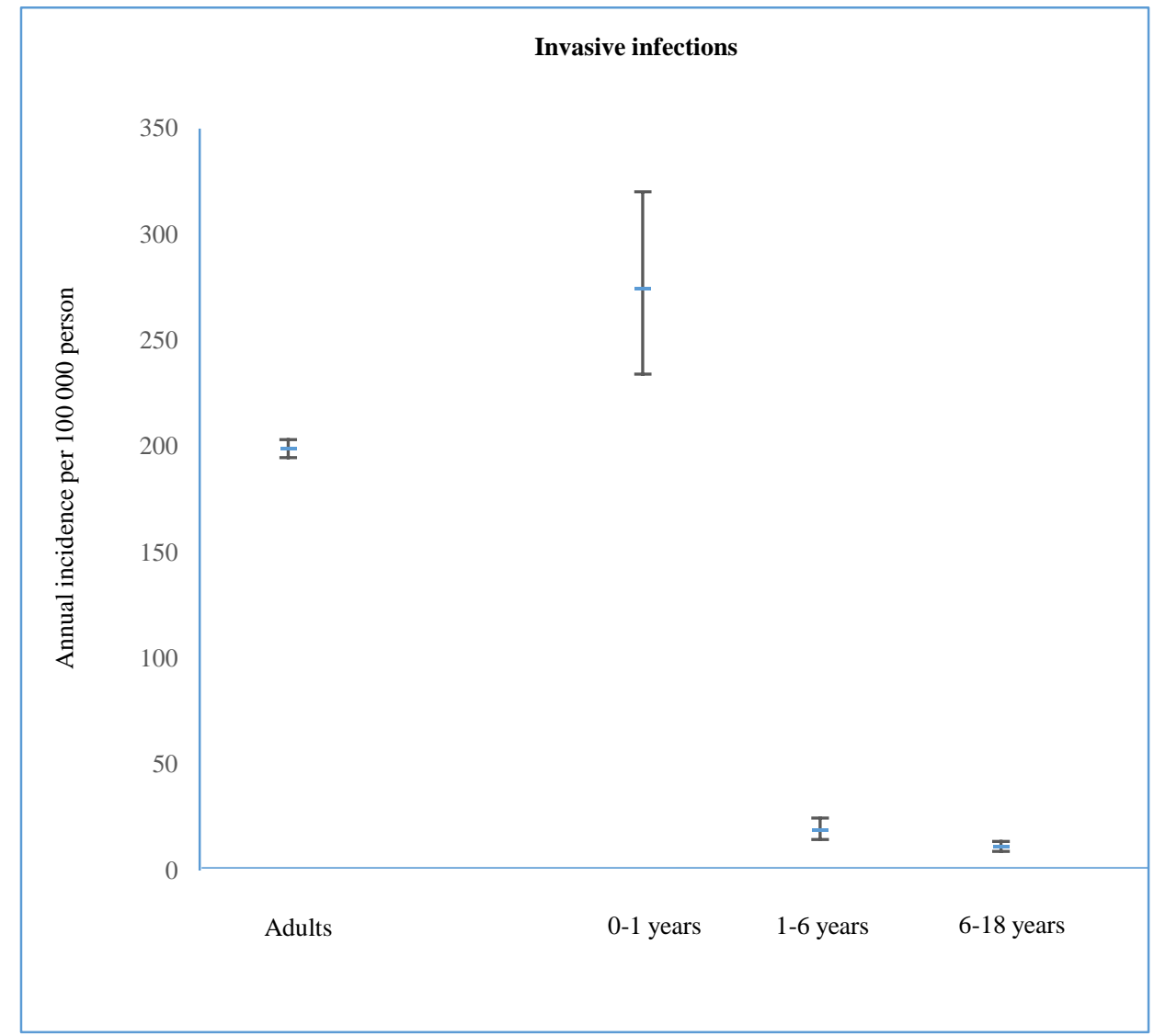




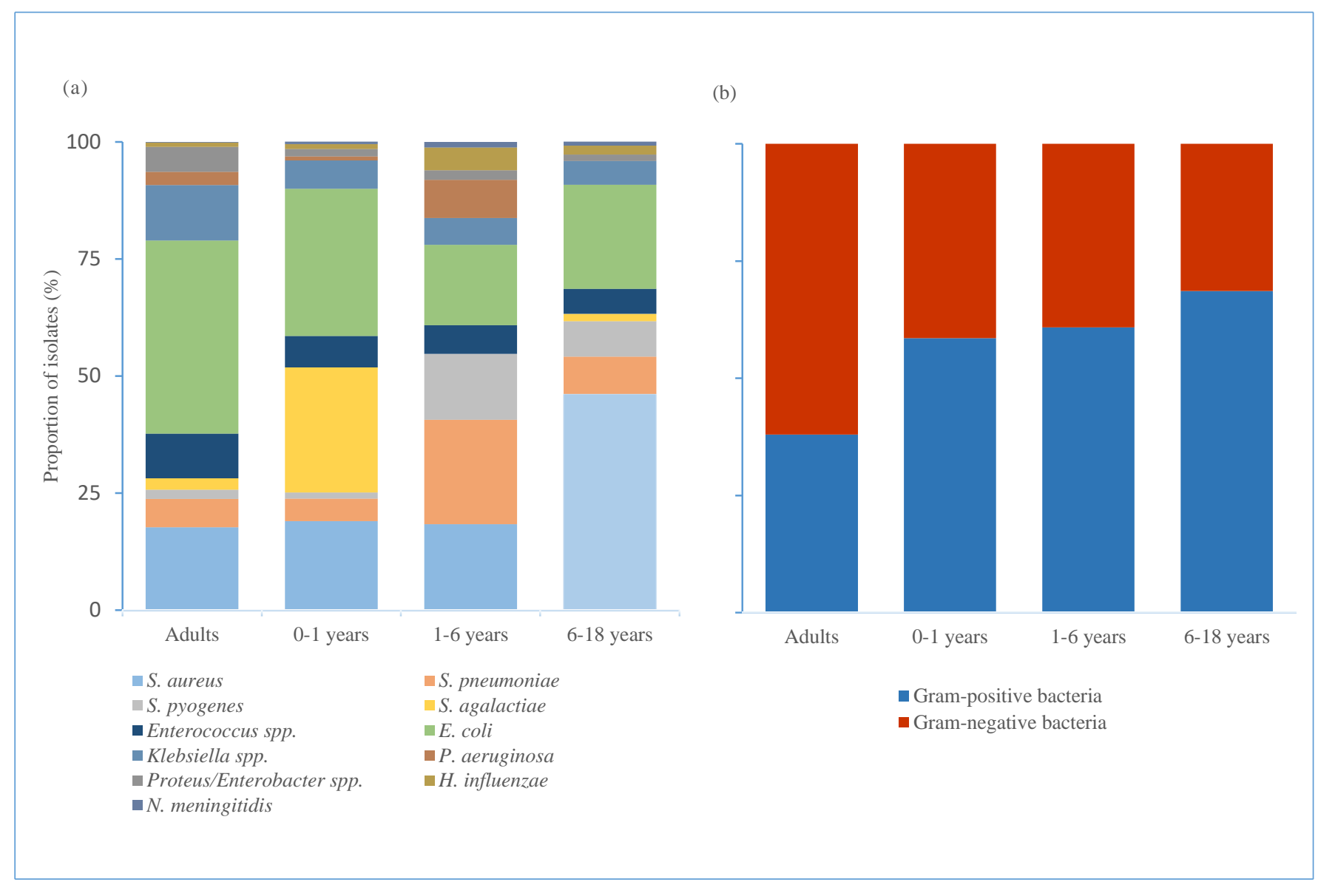




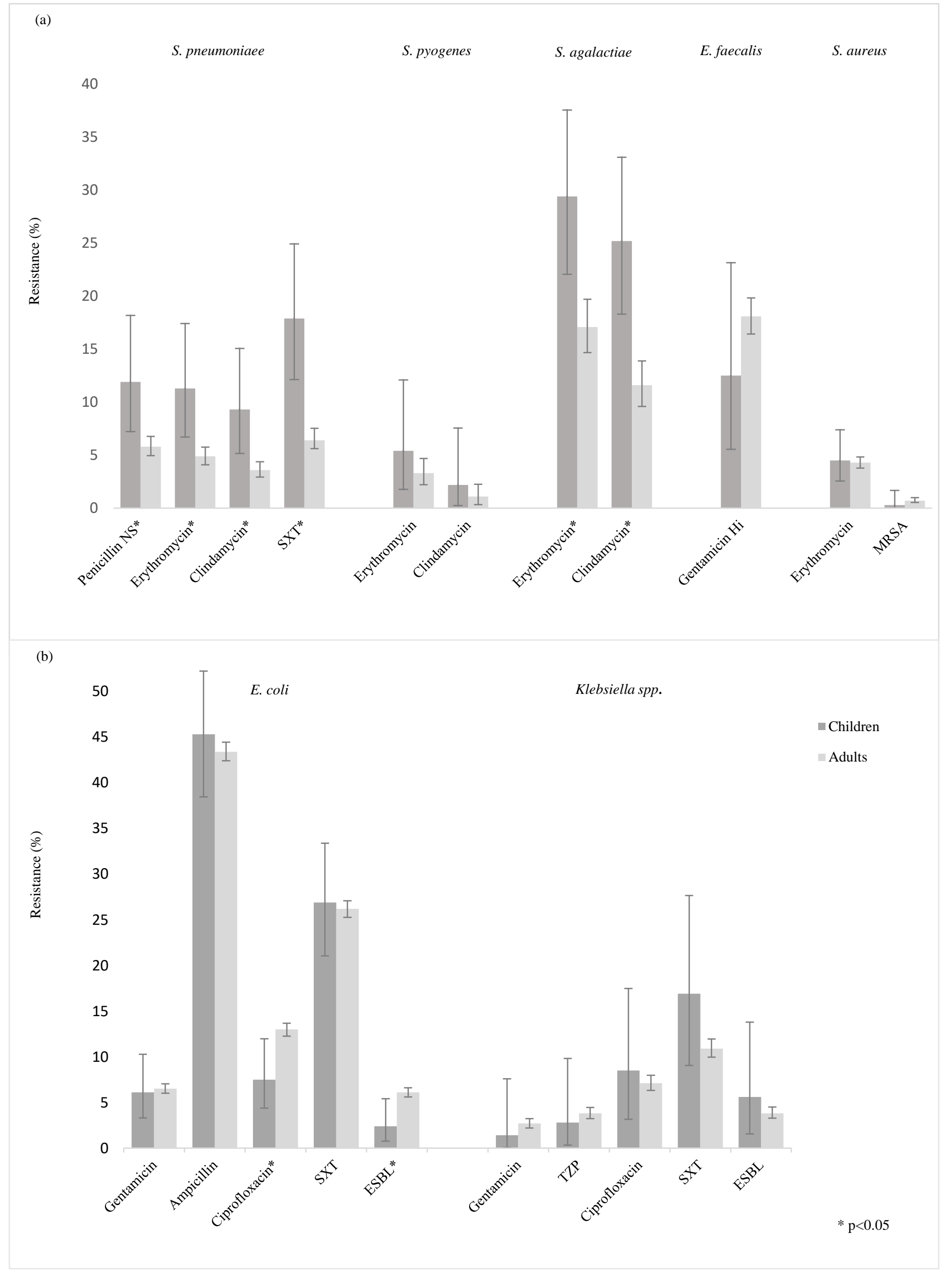




\begin{tabular}{lll|ll}
\hline & \multicolumn{2}{c|}{ Access } & & \\
\hline & $\begin{array}{l}\text { Penicillin }+ \\
\text { Gentamicin }\end{array}$ & $\begin{array}{l}\text { Ampicillin }+ \\
\text { Gentamicin }\end{array}$ & Cefotaxime & $\begin{array}{l}\text { Piperacillin- } \\
\text { tazobactam }\end{array}$ \\
\hline S. aureus & & & \\
S. pneumonia & & & \\
S. pyogenes & & & \\
S. agalactiae & & & \\
E. coli & & & \\
E. faecalis & & & \\
\hline
\end{tabular}

Go!

Resistance $<5 \%$

Be aware

*Resistance 5-10\%

* Resistance $<5 \%$, but limited clinical evidence, or increased exposure needed for $>10 \%$

No!

Resistance $>10 \%$

Access: antibiotics with less resistance potential

Watch: antibiotics with more resistance potential 


\begin{tabular}{|c|c|c|c|c|c|c|c|}
\hline & \multicolumn{3}{|c|}{ Children } & \multicolumn{3}{|c|}{ Adults } & \multirow[b]{2}{*}{$\mathbf{P}^{\#}$} \\
\hline & $\mathbf{S}^{*}, \mathbf{n}(\%)$ & $\mathbf{I}, \mathbf{n}(\%)$ & $\mathbf{R}, \mathbf{n}(\%)$ & $\mathbf{S}, \mathbf{n}(\%)$ & $\mathbf{I}, \mathbf{n}(\%)$ & $\mathbf{R}, \mathbf{n}(\%)$ & \\
\hline \multicolumn{8}{|c|}{ S. pneumoniae $(\mathrm{n}=151 / 2674)$} \\
\hline Penicillin & $133(88.1)$ & $16(10.6)$ & $2(1.3)$ & $2512(94.2)$ & $148(5.5)$ & $7(0.3)$ & 0.002 \\
\hline Erythromycin & $134(88.7)$ & $0(0.0)$ & $17(11.3)$ & $2537(95.1)$ & $0(0.0)$ & $130(4.9)$ & 0.001 \\
\hline Clindamycin & $137(90.7)$ & - & $14(9.3)$ & $2571(96.4)$ & - & $96(3.6)$ & $<0.001$ \\
\hline SXT & $120(79.5)$ & $4(2.6)$ & $27(17.9)$ & $2421(90.8)$ & $75(2.8)$ & $174(6.4)$ & $<0.001$ \\
\hline Cefotaxime & $147(97.4)$ & $4(2.6)$ & $0(0.0)$ & $2656(99.3)$ & $16(0.6)$ & $2(0.1)$ & 1.000 \\
\hline \multicolumn{8}{|l|}{ S.pyogenes $(\mathrm{n}=93 / 883)$} \\
\hline Penicillin & $93(100)$ & - & $0(0)$ & $883(100)$ & $0(0)$ & $0(0)$ & $\mathrm{n} / \mathrm{a}$ \\
\hline Erythromycin & $88(94.6)$ & $0(0.0)$ & $5(5.4)$ & $854(96.7)$ & $0(0)$ & $29(3.3)$ & 0.364 \\
\hline Clindamycin & $91(97.8)$ & - & $2(2.2)$ & $866(98.1)$ & - & $17(1.9)$ & 0.701 \\
\hline SXT & $90(96.8)$ & $0(0)$ & $3(3.2)$ & $863(97.7)$ & $3(0.3)$ & $17(1.9)$ & 0.428 \\
\hline \multicolumn{8}{|l|}{ S. agalactiae $(n=143 / 895)$} \\
\hline Penicillin & $143(100)$ & - & $0(0)$ & $895(100)$ & - & $0(0)$ & $\mathrm{n} / \mathrm{a}$ \\
\hline Erythromycin & $96(67.1)$ & $5(3.5)$ & $42(29.4)$ & $702(78.4)$ & $40(4.5)$ & $153(17.1)$ & $<0.001$ \\
\hline Clindamycin & $107(74.8)$ & - & $36(25.2)$ & $791(88.4)$ & - & $104(11.6)$ & $<0.001$ \\
\hline Vancomycin & $143(100)$ & - & $0(0)$ & $895(100)$ & - & $0(0)$ & $\mathrm{n} / \mathrm{a}$ \\
\hline \multicolumn{8}{|l|}{ E. faecalis $(n=64 / 2013)$} \\
\hline High level gentamicin & - & $56(87.5)$ & $8(12.5)$ & - & $1649(81.9)$ & $364(18.1)$ & 0.252 \\
\hline Ampicillin & $64(100)$ & $0(0.0)$ & $0(0.0)$ & $2011(99.9)$ & $1(0.0)$ & $1(0.0)$ & 1.000 \\
\hline Imipenem & $63(98.4)$ & $1(1.6)$ & $0(0.0)$ & 1990 (98.9) & $19(0.9)$ & $4(0.2)$ & 1.000 \\
\hline Vancomycin & $64(100)$ & - & $0(0.0)$ & $2011(99.9)$ & - & $2(0.1)$ & 1.000 \\
\hline \multicolumn{8}{|l|}{ S. aureus $(\mathrm{n}=\mathbf{3 3 0} / \mathbf{5 8 3 2})$} \\
\hline Beta-lactamase & $89(27.0)$ & - & $241(73.0)$ & $1626(27.9)$ & - & $4206(72.1)$ & 0.719 \\
\hline MRSA & $329(99.7)$ & - & $1(0.3)$ & $5789(99.3)$ & - & $43(0.7)$ & 0.730 \\
\hline Gentamicin & $327(99.1)$ & - & $3(0.9)$ & 5809 (99.6) & - & $23(0.4)$ & 0.160 \\
\hline Erythromycin & $315(95.5)$ & - & $15(4.5)$ & $5571(95.6)$ & $7(0.1)$ & $250(4.3)$ & 0.824 \\
\hline Clindamycin & $324(98.2)$ & $4(1.2)$ & $2(0.6)$ & $5738(98.4)$ & $24(0.4)$ & $70(1.2)$ & 0.592 \\
\hline SXT & $329(99.7)$ & $1(0.3)$ & $0(0.0)$ & 5808 (99.6) & $8(0.1)$ & $16(0.3)$ & 1.000 \\
\hline Ciprofloxacin & $324(98.2)$ & - & $6(1.8)$ & $5609(96.2)$ & - & $223(3.8)$ & 0.061 \\
\hline \multicolumn{8}{|l|}{ E. $\operatorname{coli}(n=212 / 9073)$} \\
\hline Gentamicin & $198(93.4)$ & $1(0.5)$ & $13(6.1)$ & $8445(93.1)$ & $37(0.4)$ & $591(6.5)$ & 0.824 \\
\hline Ampicillin & $116(54.7)$ & - & $96(45.3)$ & $5133(56.6)$ & - & $3940(43.4)$ & 0.590 \\
\hline Cefotaxime & $207(97.6)$ & $0(0.0)$ & $5(2.4)$ & $8484(93.5)$ & $21(0.2)$ & $568(6.3)$ & 0.020 \\
\hline Piperacillin/tazobactam & 209 (98.6) & $2(0.9)$ & $1(0.5)$ & $8548(94.2)$ & $346(3.8)$ & $179(2.0)$ & 0.197 \\
\hline Meropenem & $212(100.0)$ & $0(0.0)$ & $0(0.0)$ & $9071(100.0)$ & $2(0.0)$ & $0(0.0)$ & $\mathrm{n} / \mathrm{a}$ \\
\hline Ciprofloxacin & $191(90.1)$ & $5(2.4)$ & $16(7.5)$ & $7723(85.1)$ & 175 (1.9) & $1175(13.0)$ & 0.020 \\
\hline SXT & $154(72.6)$ & $1(0.5)$ & $57(26.9)$ & $6626(73.0)$ & $72(0.8)$ & $2375(26.2)$ & 0.816 \\
\hline ESBL & $207(97.6)$ & - & $5(2.4)$ & $8521(93.9)$ & - & $552(6.1)$ & 0.018 \\
\hline \multicolumn{8}{|c|}{ Klebsiella spp. $(\mathrm{n}=71 / 3897)^{\&}$} \\
\hline Gentamicin & $70(98.6)$ & $0(0.0)$ & $1(1.4)$ & $3774(96.8)$ & $19(0.5)$ & $104(2.7)$ & 1.000 \\
\hline Cefotaxime & $67(94.4)$ & $1(1.4)$ & $3(4.2)$ & $3726(95.6)$ & $19(0.5)$ & $152(3.9)$ & 0.756 \\
\hline Piperacillin/tazobactam & $66(93.0)$ & $3(4.2)$ & $2(2.8)$ & $3461(88.8)$ & $288(7.4)$ & $148(3.8)$ & 1.000 \\
\hline SXT & $58(81.7)$ & $1(1.4)$ & $12(16.9)$ & $3428(88.0)$ & $43(1.1)$ & $426(10.9)$ & 0.112 \\
\hline Ciprofloxacin & $64(90.1)$ & $1(1.4)$ & $6(8.5)$ & $3503(89.9)$ & $117(3.0)$ & $277(7.1)$ & 0.663 \\
\hline ESBL & $67(94.4)$ & - & $4(5.6)$ & 3747 (96.2) & - & $150(3.8)$ & 0.355 \\
\hline
\end{tabular}


SDC 1) Susceptibility pattern in Norwegian invasive (blood/CSF) isolates in children (0-18 years) and adults based on sampling from the Norwegian Surveillance System for Antimicrobial Drug Resistance (NORM) 2013-2017. SXT; trimethoprim/sulfamethoxazole

* $\mathrm{S}=$ susceptible, $\mathrm{I}=$ intermediate resistant, $\mathrm{R}=$ resistant

\# Chi squared test comparing R with SI, except for S. pneumoniae/Penicillin G were we compared S with RI. Fisher`s exact test was used if any expected frequency $<5$

\& Children: Klebsiella pneumonia (55, 77.5\%), Klebsiella oxytoca (13, 18.3\%), not identified species (3, 4.2\%), Adults: Klebsiella pneumonia $(3071,77.4 \%)$, Klebsiella oxytoca $(746,18.8 \%)$, not identified species $(151,3.8 \%)$ 


\begin{tabular}{|c|c|c|c|c|c|c|c|c|c|c|c|}
\hline & \multicolumn{2}{|c|}{2013} & \multicolumn{2}{|c|}{2014} & \multicolumn{2}{|r|}{2015} & \multicolumn{2}{|c|}{2016} & \multicolumn{2}{|c|}{2017} & \multirow[t]{2}{*}{$\mathbf{P}^{*}$} \\
\hline & $\begin{array}{l}\text { Total } \\
\text { n }\end{array}$ & $\begin{array}{l}\text { Resistant } \\
\text { n(\%) }\end{array}$ & $\begin{array}{l}\text { Total } \\
\text { n }\end{array}$ & $\begin{array}{l}\text { Resistant } \\
\mathbf{n}(\%)\end{array}$ & $\begin{array}{l}\text { Total, } \\
\text { n }\end{array}$ & $\begin{array}{l}\text { Resistant } \\
\mathbf{n}(\%)\end{array}$ & $\begin{array}{l}\text { Total } \\
\text { n }\end{array}$ & $\begin{array}{l}\text { Resistant } \\
\mathbf{n}(\%)\end{array}$ & $\begin{array}{l}\text { Total } \\
\text { n }\end{array}$ & $\begin{array}{l}\text { Resistant } \\
\mathbf{n}(\%)\end{array}$ & \\
\hline \multicolumn{12}{|l|}{ Children } \\
\hline \multicolumn{12}{|l|}{ S. pneumoniae } \\
\hline Penicillin NS & 33 & $2(6.1)$ & 28 & $5(17.9)$ & 27 & $3(11.1)$ & 39 & $1(2.6)$ & 24 & $7(29.2)$ & 0.017 \\
\hline Erythromycin & 33 & $0(0.0)$ & 28 & $5(17.9)$ & 27 & $1(3.7)$ & 39 & $3(7.7)$ & 24 & $8(33.3)$ & 0.001 \\
\hline Clindamycin & 33 & $0(0.0)$ & 28 & $4(14.3)$ & 27 & $1(3.7)$ & 39 & $1(2.6)$ & 24 & $8(33.3)$ & 0.000 \\
\hline SXT & 33 & $3(9.1)$ & 28 & $5(17.9)$ & 27 & $8(29.6)$ & 39 & $5(12.8)$ & 24 & $6(25.0)$ & 0.215 \\
\hline \multicolumn{12}{|l|}{ S. pyogenes } \\
\hline Erythromycin & 13 & $0(0.0)$ & 20 & $0(0.0)$ & 18 & $2(11.1)$ & 16 & $1(6.3)$ & 26 & $2(7.7)$ & 0.572 \\
\hline \multicolumn{12}{|l|}{ S. agalactiae } \\
\hline Erythromycin & $\mathrm{n} / \mathrm{a}$ & $\mathrm{n} / \mathrm{a}$ & 47 & $10(21.3)$ & 50 & $12(24.0)$ & 14 & $6(42.9)$ & 32 & $14(43.8)$ & 0.079 \\
\hline Clindamycin & $\mathrm{n} / \mathrm{a}$ & $\mathrm{n} / \mathrm{a}$ & 47 & $9(19.2)$ & 50 & $9(18.0)$ & 14 & $7(50.0)$ & 32 & $11(34.4)$ & 0.040 \\
\hline \multicolumn{12}{|l|}{ E. faecalis } \\
\hline High level gentamicin & 12 & $3(25.0)$ & 12 & $0(0.0)$ & 15 & $1(6.7)$ & 12 & $2(16.7)$ & 13 & $2(15.4)$ & 0.396 \\
\hline S. aureus & & & & & & & & & & & \\
\hline Beta-lactamase & 81 & $61(75.3)$ & 62 & $43(69.4)$ & 70 & $51 / 72.9)$ & 45 & $33(73.3)$ & 72 & $53(73.6)$ & 0.957 \\
\hline Erythromycin & 81 & $4(4.9)$ & 62 & $0(0.0)$ & 70 & $3(4.3)$ & 45 & $5(11.1)$ & 72 & $3(4.2)$ & 0.099 \\
\hline Ciprofloxacin & 81 & $0(0.0)$ & 62 & $1(1.6)$ & 70 & $1(1.4)$ & 45 & $1(2.2)$ & 72 & $3(4.2)$ & 0.376 \\
\hline E.coli & & & & & & & & & & & \\
\hline Gentamicin & 33 & $3(9.1)$ & 35 & $2(5.7)$ & 46 & $2(4.3)$ & 47 & $2(4.3)$ & 51 & $4(7.8)$ & 0.870 \\
\hline Ampicillin & 33 & $18(54.6)$ & 35 & $16(45.7)$ & 46 & $22(47.8)$ & 47 & $13(27.7)$ & 51 & $27(52.9)$ & 0.079 \\
\hline Cefotaxime & 33 & $1(3.0)$ & 35 & $0(0.0)$ & 46 & $0(0.0)$ & 47 & $1(2.1)$ & 51 & $3(5.9)$ & 0.368 \\
\hline Ciprofloxacin & 33 & $3(9.1)$ & 35 & $1(2.9)$ & 46 & $2(4.4)$ & 47 & $2(4.3)$ & 51 & $8(15.7)$ & 0.160 \\
\hline SXT & 33 & $13(39.4)$ & 35 & $10(28.6)$ & 46 & $16(34.8)$ & 47 & $5(10.6)$ & 51 & $13(25.5)$ & 0.033 \\
\hline ESBL & 33 & $1(3.0)$ & 35 & $0(0.0)$ & 46 & $0(0.0)$ & 47 & $1(2.1)$ & 51 & $3(5.9)$ & 0.368 \\
\hline Klebsiella spp. & & & & & & & & & & & \\
\hline SXT & 10 & $5(50.0)$ & 9 & $1(11.1)$ & 12 & $0(0.0)$ & 25 & $2(8.0)$ & 15 & $4(26.7)$ & 0.012 \\
\hline ESBL & 10 & $1(10.0)$ & 9 & $0(0.0)$ & 12 & $0(0.0)$ & 25 & $1(4.0)$ & 15 & $2(13.3)$ & 0.479 \\
\hline Ciprofloxacin & 10 & $0(0.0)$ & 9 & $0(0.0)$ & 12 & $0(0.0)$ & 25 & $3(12.0)$ & 15 & $3(20.0)$ & 0.286 \\
\hline Adults & & & & & & & & & & & \\
\hline S. pneumoniae & & & & & & & & & & & \\
\hline Penicillin NS & 575 & $17(3.0)$ & 533 & $26(4.9)$ & 492 & $36(7.3)$ & 555 & $31(5.6)$ & 512 & $45(8.8)$ & 0.001 \\
\hline Erythromycin & 575 & $22(3.8)$ & 533 & $20(3.8)$ & 492 & $24(4.9)$ & 555 & $30(5.4)$ & 512 & $34(6.6)$ & 0.159 \\
\hline Clindamycin & 575 & $15(2.6)$ & 533 & $14(2.6)$ & 492 & $18(3.7)$ & 555 & $24(4.3)$ & 512 & $25(4.9)$ & 0.174 \\
\hline SXT & 575 & $20(3.5)$ & 533 & $30(5.6)$ & 492 & $41(8.3)$ & 555 & $42(7.6)$ & 512 & $38(7.4)$ & 0.008 \\
\hline S. pyogenes & & & & & & & & & & & \\
\hline Erythromycin & 149 & $3(2.0)$ & 168 & $7(4.2)$ & 182 & $5(2.8)$ & 171 & $6(3.5)$ & 213 & $8(3.8)$ & 0.829 \\
\hline Clindamycin & 149 & $1(0.7)$ & 168 & $4(2.4)$ & 182 & $3(1.7)$ & 171 & $3(1.8)$ & 213 & $6(2.8)$ & 0.690 \\
\hline SXT & 149 & $5(3.4)$ & 168 & $5(3.0)$ & 182 & $2(1.1)$ & 171 & $3(1.8)$ & 213 & $2(0.9)$ & 0.356 \\
\hline S. agalactiae & & & & & & & & & & & \\
\hline Erythromycin & $\mathrm{n} / \mathrm{a}$ & $\mathrm{n} / \mathrm{a}$ & 196 & $34(17.4)$ & 229 & 38 (16.6) & 267 & $42(15.7)$ & 203 & 39 (19.2) & 0.791 \\
\hline Clindamycin & $\mathrm{n} / \mathrm{a}$ & $\mathrm{n} / \mathrm{a}$ & 196 & $22(11.2)$ & 229 & $30(13.1)$ & 267 & $28(10.5)$ & 203 & $24(11.8)$ & 0.835 \\
\hline E. faecalis & & & & & & & & & & & \\
\hline High level gentamicin & 401 & $94(23.4)$ & 395 & $76(19.2)$ & 368 & $49(13.3)$ & 409 & $77(18.8)$ & 440 & $68(15.5)$ & 0.003 \\
\hline S. aureus & & & & & & & & & & & \\
\hline Beta-lactamase & 1074 & 772 (71.9) & 1101 & $805(73.1)$ & 1207 & $881(73.0)$ & 1210 & 879 (72.6) & 1240 & $869(70.1)$ & \\
\hline MRSA & 1074 & $3(0.3)$ & 1101 & $9(0.8)$ & 1207 & $8(0.7)$ & 1210 & $13(1.1)$ & 1240 & $10(0.8)$ & 0.265 \\
\hline Erythromycin & 1070 & $41(3.8)$ & 1101 & $47(4.3)$ & 1207 & $66(5.5)$ & 1210 & $59(4.9)$ & 1240 & $37(3.0)$ & 0.029 \\
\hline Clindamycin & 1074 & $17(1.6)$ & 1101 & $9(0.8)$ & 1207 & $20(1.7)$ & 1210 & $16(1.3)$ & 1240 & $8(0.7)$ & 0.085 \\
\hline SXT & 1074 & $6(0.6)$ & 1101 & $0(0.0)$ & 1207 & $4(0.3)$ & 1210 & $3(0.3)$ & 1240 & $3(0.2)$ & 0.132 \\
\hline Ciprofloxacin & 1074 & $33(3.1)$ & 1101 & $32(2.9)$ & 1207 & $28(2.3)$ & 1210 & $86(7.1)$ & 1240 & $44(3.6)$ & 0.000 \\
\hline Gentamicin & 1074 & $3(0.3)$ & 1101 & $5(0.5)$ & 1207 & $2(0.2)$ & 1210 & $5(0.4)$ & 1240 & $8(0.7)$ & 0.404 \\
\hline E. coli & & & & & & & & & & & \\
\hline Gentamicin & 1579 & $87(5.6)$ & 1610 & $125(7.8)$ & 1906 & $113(5.9)$ & 1893 & $120(6.3)$ & 2085 & $146(7.0)$ & 0.068 \\
\hline Ampicillin & 1579 & $670(42.4)$ & 1610 & $685(42.6)$ & 1906 & $839(44.0)$ & 1893 & $831(43.9)$ & 2085 & $915(43.9)$ & 0.779 \\
\hline Cefotaxime & 1579 & $86(5.5)$ & 1610 & $100(6.2)$ & 1906 & $127(6.7)$ & 1893 & $115(6.1)$ & 2085 & $140(6.7)$ & 0.531 \\
\hline Piperacillin/tazobactam & 1579 & $34(2.2)$ & 1610 & $47(2.9)$ & 1906 & $29(1.5)$ & 1893 & $37(2.0)$ & 2085 & $32(1.5)$ & 0.019 \\
\hline Ciprofloxacin & 1579 & $187(11.8)$ & 1610 & $206(12.8)$ & 1906 & $222(11.7)$ & 1893 & $243(12.8)$ & 2085 & $317(15.2)$ & 0.007 \\
\hline SXT & 1579 & $397(25.1)$ & 1610 & $447(27.8)$ & 1906 & $509(26.7)$ & 1893 & $495(26.2)$ & 2085 & $527(25.3)$ & 0.389 \\
\hline ESBL & 1579 & $80(5.1)$ & 1610 & $95(5.9)$ & 1906 & $127(6.7)$ & 1893 & $112(5.9)$ & 2085 & $138(6.6)$ & 0.266 \\
\hline Klebsiell & & & & & & & & & & & \\
\hline Gentamicin & 642 & $7(1.1)$ & 745 & $19(2.6)$ & 811 & $22(2.7)$ & 830 & $29(3.5)$ & 869 & $27(3.1)$ & 0.061 \\
\hline Cefotaxime & 642 & $15(2.3)$ & 745 & $27(3.6)$ & 811 & $24(3.0)$ & 830 & $40(4.8)$ & 869 & $46(5.3)$ & 0.013 \\
\hline
\end{tabular}




\begin{tabular}{|c|c|c|c|c|c|c|c|c|c|c|c|}
\hline ESBL & 642 & $17(2.7)$ & 745 & $26(3.5)$ & 811 & $24(3.0)$ & 830 & $38(4.6)$ & 869 & $45(5.2)$ & 0.043 \\
\hline Piperacillin/tazobactam & 642 & $23(3.6)$ & 745 & $29(3.9)$ & 811 & $27(3.3)$ & 830 & $34(4.1)$ & 869 & $35(4.0)$ & 0.922 \\
\hline SXT & 64 & $64(10.0)$ & 745 & $71(9.5)$ & 811 & $80(9.9)$ & 830 & $91(11.0)$ & 869 & $120(13.8)$ & 0.033 \\
\hline Ciprofloxacin & 642 & $19(3.0)$ & 745 & $30(4.0)$ & 811 & 29 (3.6) & 830 & $93(11.2)$ & 869 & $106(12.2)$ & 0.000 \\
\hline
\end{tabular}

SDC 2a) Year-by-year resistance rates in invasive (blood/CSF) bacterial isolates for children (0-18 years) and adults from the Norwegian Surveillance System for Antimicrobial Drug Resistance (NORM). SXT; trimethoprim/sulfamethoxazole; Penicillin NS; penicillin nonsusceptibility

* Chi squared test comparing proportion of resistance. Fisher`s exact test was used if any expected frequency $<5$.

\begin{tabular}{|c|c|c|c|}
\hline & $\mathrm{S}^{*}, \mathrm{n}(\%)$ & $\mathrm{I}, \mathrm{n}(\%)$ & $\mathrm{R}, \mathrm{n}(\%)$ \\
\hline \multicolumn{4}{|l|}{ E. faecium $(\mathrm{n}=9)$} \\
\hline Ampicillin & $2(22.2)$ & $0(0.0)$ & $7(77.8)$ \\
\hline Gentamicin & $9(100.0)$ & - & $0(0.0)$ \\
\hline Imipenem & $1(11.1)$ & $1(11.1)$ & $7(88.8)$ \\
\hline Vancomycin & $9(100.0)$ & - & $0(0.0)$ \\
\hline \multicolumn{4}{|l|}{ H. influenzae $(\mathrm{n}=34)$} \\
\hline Beta-lactamase & $32(94.1)$ & - & $2(5.9)$ \\
\hline Ampicillin & $31(91.2)$ & - & $3(8.8)$ \\
\hline Cefotaxime & $34(100.0)$ & - & $0(0.0)$ \\
\hline Ciprofloxacin & $34(100.0)$ & - & $0(0.0)$ \\
\hline Trimethoprim/sulfamethoxazole & $30(88.2)$ & - & $4(11.8)$ \\
\hline \multicolumn{4}{|l|}{$N$. meningitidis $(\mathrm{n}=12)$} \\
\hline Penicillin G & $6(50.0)$ & $5(41.7)$ & $1(8.3)$ \\
\hline Ceftriaxone & $12(100.0)$ & - & $0(0.0)$ \\
\hline Azithromycin & $12(100.0)$ & - & $0(0.0)$ \\
\hline \multicolumn{4}{|l|}{ P. aeruginosa $(\mathrm{n}=5)$} \\
\hline Gentamicin & $5(100.0)$ & - & $0(0.0)$ \\
\hline Tobramycin & $5(100.0)$ & - & $0(0.0)$ \\
\hline Ceftazidime & $4(80.0)$ & - & $1(20.0)$ \\
\hline
\end{tabular}

SDC $2 b$ ) Susceptibility pattern for selected bacteria in invasive (blood/CSF) isolates in children (0-18 years) from the Norwegian Surveillance System for Antimicrobial Drug Resistance (NORM) 2013-2017

* S (sensitive), I (intermediate resistant), R (resistant) 


\begin{tabular}{|c|c|c|c|c|}
\hline & $\begin{array}{l}\text { 0-1 years } \\
\%(95 \% \mathrm{CI})\end{array}$ & $\begin{array}{l}1-6 \text { years } \\
\%(95 \% \mathrm{CI})\end{array}$ & $\begin{array}{l}\text { 6-18 years } \\
\%(95 \% \mathrm{CI})\end{array}$ & P-value* \\
\hline \multicolumn{5}{|l|}{ S. pneumonia } \\
\hline All isolates, $\mathrm{n}$ & 40 & 73 & 38 & \\
\hline \multicolumn{5}{|l|}{ Resistance rates, \% (95\% CI) } \\
\hline Penicillin NS & $5.0(0.6-16.9)$ & $13.7(6.8-23.8)$ & $15.8(6.0-31.3)$ & 0.252 \\
\hline Erythromycin & $7.5(1.6-20.4)$ & $11.0(4.9-20.5)$ & $15.8(6.0-31.3)$ & 0.530 \\
\hline Clindamycin & $7.5(1.6-20.4)$ & $8.2(3.1-17.0)$ & $13.2(4.4-28.1)$ & 0.670 \\
\hline SXT & $7.5(1.6-20.4)$ & $24.7(15.3-36.1)$ & $15.8(6.0-31.3)$ & 0.070 \\
\hline Multi-resistance ${ }^{\#}$ & $2.5(0.06-13.2)$ & $9.6(3.9-18.8)$ & $7.9(1.7-21.4)$ & 0.685 \\
\hline \multicolumn{5}{|l|}{ S. aureus } \\
\hline All isolates, $\mathrm{n}$ & 119 & 45 & 165 & \\
\hline \multicolumn{5}{|l|}{ Resistance rates, \% (95\% CI) } \\
\hline Beta-lactamase & $79.0(70.1-85.9)$ & $73.3(58.1-85.4)$ & $68.3(60.6-75.3)$ & 0.135 \\
\hline Erythromycin & $7.6(3.5-13.9)$ & $2.2(0.06-11.8)$ & $3.1(1.0-7.0)$ & 0.167 \\
\hline Ciprofloxacin & $0.8(0.2-4.6)$ & $4.4(0.5-15.1)$ & $1.8(0.4-5.3)$ & 0.237 \\
\hline \multicolumn{5}{|l|}{ E. coli } \\
\hline All isolates, $\mathrm{n}$ & 131 & 28 & 53 & \\
\hline \multicolumn{5}{|l|}{ Resistance rates, \% (95\% CI) } \\
\hline Gentamicin & $3.8(1.3-8.7)$ & $7.1(0.9-23.5)$ & $11.3(4.3-23.0)$ & 0.121 \\
\hline Ampicillin & $42.0(33.4-50.9)$ & $39.3(21.5-59.4)$ & $56.6(42.3-70.2)$ & 0.155 \\
\hline Ciprofloxacin & $6.1(2.7-11.7)$ & $7.1(0.9-23.5)$ & $11.3(4.3-23.0)$ & 0.442 \\
\hline SXT & $19.6(13.4-27.8)$ & $28.6(13.2-48.7)$ & $43.4(29.8-57.7)$ & 0.005 \\
\hline ESBL & $2.3(0.5-6.5)$ & $7.1(0.9-23.5)$ & $0.0(0.0-6.7)$ & 0.120 \\
\hline
\end{tabular}

SDC 3) Comparison of resistance rates for selected bacteria between different age-groups in Norwegian children, 2013-2017. Penicillin NS; penicillin nonsusceptibility; SXT; trimethoprim/sulfamethoxazole

\footnotetext{
$*$ Chi squared test comparing the proportion of resistant isolates. Fisher`s exact test was used if any expected frequency $<5$.

\# Resistant (or non-susceptible to penicillin) to three or more of the antibiotics above
} 


\begin{tabular}{lll|ll}
\hline & \multicolumn{2}{c|}{ Access } & & \\
\hline & $\begin{array}{l}\text { Penicillin }+ \\
\text { Gentamicin }\end{array}$ & $\begin{array}{l}\text { Ampicillin }+ \\
\text { Gentamicin }\end{array}$ & Cefotaxime & $\begin{array}{l}\text { Piperacillin- } \\
\text { tazobactam }\end{array}$ \\
\hline S. aureus & & & \\
S. pneumonia & & & \\
S. pyogenes & & & \\
S. agalactiae & & & \\
E. coli & & & \\
E. faecalis & & & \\
\hline
\end{tabular}

Go!

Resistance $<5 \%$

Be aware

*Resistance 5-10\%

* Resistance $<5 \%$, but limited clinical evidence, or increased exposure needed for $>10 \%$

No!

Resistance $>10 \%$

Access: antibiotics with less resistance potential

Watch: antibiotics with more resistance potential 